\title{
EVOLUTION OF SPATIAL ABILITY IN FRESHMAN ENGINEERING STUDENTS: A COMPARISON BETWEEN 2012 AND 2019 COHORTS
}

\author{
Roberto Llorens ${ }^{1,2}$, Manuel Contero', Mariano Alcañiz ${ }^{1}$ \\ ${ }^{1}$ Instituto de Investigación e Innovación en Bioingeniería, Universitat Politècnica de València, \\ (SPAIN) \\ ${ }^{2} N E U R O R H B$. Servicio de Neurorrehabilitación de Hospitales Vithas (SPAIN)
}

\begin{abstract}
This study makes a comparison between the level of spatial skills of freshman students enrolled on the Bachelor's Degree in Industrial Engineering at Universitat Politècnica de Valencia (Spain) between the years 2012 and 2019 measured using the Mental Rotations Test (MRT) and the Differential Aptitude Test: Space Relations subset (DAT:SR). Spatial skills are a determining factor for success in technical studies, so it is important to know how the level of these skills has evolved over time for new students arriving at the University. The article presents an introduction to the field of spatial skills and how they are usually evaluated, and present the results obtained from a sample of 55 students in 2012 and 158 in the 2019 course. Online versions of the MRT and DAT:SR were administered to investigate how the performance of the students evolved throughout the execution of the test. A notable worsening in the success rate was evidenced as the test progressed in both cohorts. Results showed comparable mean scores in the DAT:SR in both cohorts and a slightly better performance in the MRT for the 2019 cohort
\end{abstract}

Keywords: spatial skill, freshman engineering students, mental rotations test, differential aptitude test.

\section{INTRODUCTION}

From an academic standpoint, the development of 3D spatial skills has been cited and recognized by many authors as a key factor in many scientific and technical disciplines [1, 2]. Studies have consistently shown that proper spatial skills are directly related to academic success in science, technology, engineering, and mathematics $[3,4,5]$.

Spatial ability, as one of the main components of human intelligence, is a well-studied topic in Psychology, and also in other fields, which explains the different approaches and classifications that can be found in the literature. Some authors classify the spatial ability in several sub-abilities, each referring to different aspects $[6,7]$. "Spatial Relation" refers to the ability of performing tasks that require the mental rotation of simple two-dimensional or three-dimensional objects [8]. "Spatial Visualization" refers to the ability to manipulate complex spatial information when several stages are needed to produce the correct solution. "Spatial Orientation" refers to the ability to perform tasks in which a given object or an array of objects has to be imagined from another perspective.

Other authors simplify this classification by identifying only two categories $[9,10]:$ "Spatial Relation", which includes spatial relation and spatial orientation as previously described, and "Spatial Visualization", as the mental manipulation and integration of stimuli consisting of more than one part or movable parts, where movement of the internal parts of a complex configuration and/or the folding and unfolding of flat patterns is usually involved.

Following the latest approaches within the field of research on human intelligence, from a psychometric perspective, spatial ability is identified as a second-order factor called Visual Processing (Gv). The Cattell-Horn-Carroll Model of intelligence defines visual processing as the ability to make use of simulated mental imagery (often in conjunction with currently perceived images) to solve problems [11]. This model includes several subfactors that are related to the sub-abilities described before.

The assessment of spatial abilities is commonly performed using standardized tests [12], which have consistently shown diminished spatial ability in women, compared to men [13]. The most widely used instruments in studies about the development of spatial abilities in engineering students are described in the next section [14]. 
The rapid advance in the development of technology is changing in a remarkable way the type of stimuli that children and adolescents receive. This study aims to analyze how the level of spatial skills of first-year engineering students has changed, taking the years 2012 and 2019 as a reference. In this 7-year period, there has been a very rapid evolution of functionality and interaction capabilities of multitouch devices and videogames. As a proof, the students who entered the university in 2019, were around 7-8 years old when tablets and mobile phones with multi-touch interfaces hit the market, and have access to second and third generation game consoles, with graphic features far superior to the first models of game consoles on the market.

Consequently, the hypotheses of this study were: first, that the 2019 cohort would have developed improved spatial abilities derived from their exposure to more advanced technological devices, which would be evidenced as higher scores in spatial ability tests; and second, that men would have better performance in the tests than women, as increased spatial ability has been associated to men.

\section{MEASURING SPATIAL ABILITIES}

\subsection{Mental Cutting Test}

The standard Mental Cutting Test [15] consists of 25 items, each presenting a perspective of an object and a cutting plane. The subject must choose the figure that correctly matches the resulting section. Some of the items have relatively unusual shapes and have a significant level of difficulty [16]. The Mental Cutting Test takes 20 minutes and provides a numerical score out of 25.

\subsection{Mental Rotation Test}

The MRT [17] consists of 20 items, divided into two 10-item sets that must be completed in three minutes. Each item includes five three-dimensional objects comprised of different cubes, one being a target and the remaining four being possible alternatives that matches or not the target object (two correct alternatives and two incorrect alternatives). Correct alternatives are structurally identical to the target but shown in a rotated position. The subjects are asked to find the two correct alternatives and are awarded with two points if they succeed. One point is received if only one of the correct options is chosen. No points are scored if the subject choses one or both incorrect options. The maximum score that can be obtained is 40 .

\subsection{Differential Aptitude Test: Space Relations}

The DAT:SR [18] consists of 50 items where the subject must select an appropriate 3D object among four possible alternatives, which illustrate correct or incorrect illustrations presumably obtained by folding the given unfolded shape. The DAT:SR test takes 20 minutes and the result is a numerical score out of 50 .

\subsection{Purdue Spatial Visualization Tests: Rotations and its revised version}

The Purdue Spatial Visualization Tests: Rotations [19] consists of 30 items. For each item, a given object is rotated in space. Then a set of five choices are presented that show a presumable rotated version of the already rotated object. Subjects have to select the object resulting from applying the same amount of rotation as to the original object to the second object. The test takes 20 minutes.

The Revised Purdue Spatial Visualization Test: Visualization of Rotations [20] is a revised version of the previous test. This revised version has two practice items followed by 30 test items that consist of 13 symmetrical and 17 asymmetrical figures of 3-D objects, which are drawn in isometric perspective. In the revised version, figures are rescaled, and items are reordered from easy to difficult.

\subsection{Purdue Spatial Visualization Tests: Visualization}

The Purdue Spatial Visualization Tests: Visualization [19] consists of 30 items. Participants are given an object framed in a clear box and must visualize it from a specific point of view that is marked with a dot. Five alternatives are offered, from which only one is correct. 


\subsection{Purdue Spatial Visualization Tests: Development}

The Purdue Spatial Visualization Tests: Development [19] consists of 30 items that show the development of different objects. Participants must identify among five options, the only correct alternative that corresponds with the object whose development is shown, presented by its axonometric projection.

\subsection{Spatial Orientation Test}

The Spatial Orientation Test [21] consists of 12 items. In each of them, seven objects are presented. Participants are asked to imagine being at the position of one object (the station point) facing another object and then are asked to indicate the direction to a third object (target). The score for each item is obtained by measuring the absolute deviation in degrees between the participant's response and the correct direction to the target (absolute directional error). The participant's total score is calculated as the average deviation across all items.

\section{METHODOLOGY}

\subsection{Participants}

This study enrolled freshman engineering students who were undertaking studies in the "Graphic Expression" course of the first academic year of the Engineering Technology undergraduate degree program at the School of Industrial Engineering of Universitat Politècnica de València. A total of 55 students in the 2012 cohort (12 women and 43 men) and 158 students (46 women and 112 men) in the 2019 cohort participated in the study.

\subsection{Procedure}

The spatial ability of the participants were examined using online versions of the 20 -item version of the MRT [17], which assessed the spatial relation, and the 50-item version of the DAT:SR [18], which assessed the spatial visualization.

\subsection{Data analysis}

Progression of the performance throughout the test was investigated from the percentage of students who answered each item and the percentage of students who obtained the maximum score in each item.

Normality of the data was rejected using Kolmogorov-Smirnov tests. Differences between cohorts and sexes were investigated using Mann Whitney $U$ tests.

\section{RESULTS}

\subsection{Progression of the performance throughout the tests}

The percentage of students who answered each item and the percentage of students who obtained the maximum score in each item in the MRT are shown in Figure 1 and Figure 2, respectively. Both figures illustrate a dramatic decrease of the performance as the test progresses. The polynomial curve that better fits the sets of data points is also illustrated. 


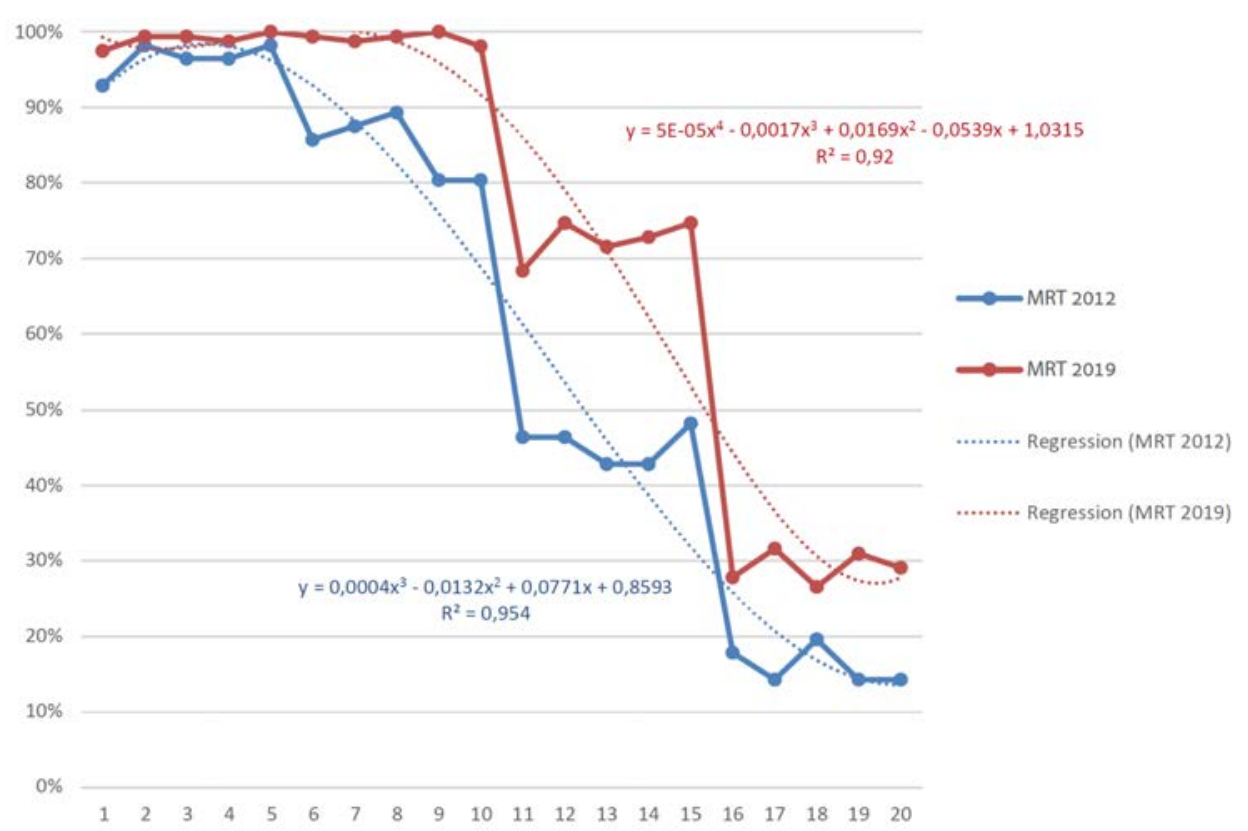

Figure 1. Percentage of students who answered each item of the Mental Rotation Test

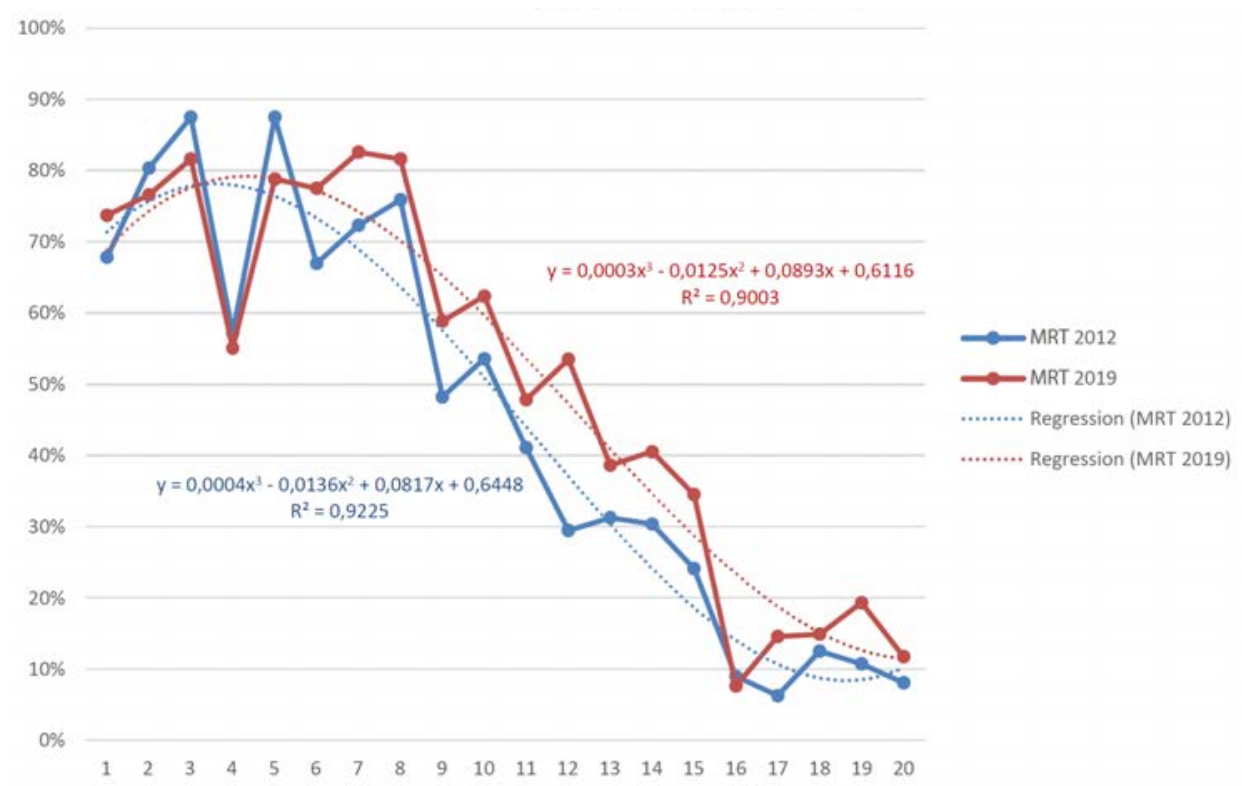

Figure 2. Percentage of students who obtained the maximum score in each item of the Mental Rotation Test

A very similar decrease of the performance as the test progressed was shown in the DAT:SR. Figure 3 and Figure 4 illustrate the percentage of students who answered each item and the percentage of students who obtained the maximum score in each item in this test. The polynomial curve that better fits the sets of data points is also illustrated. 


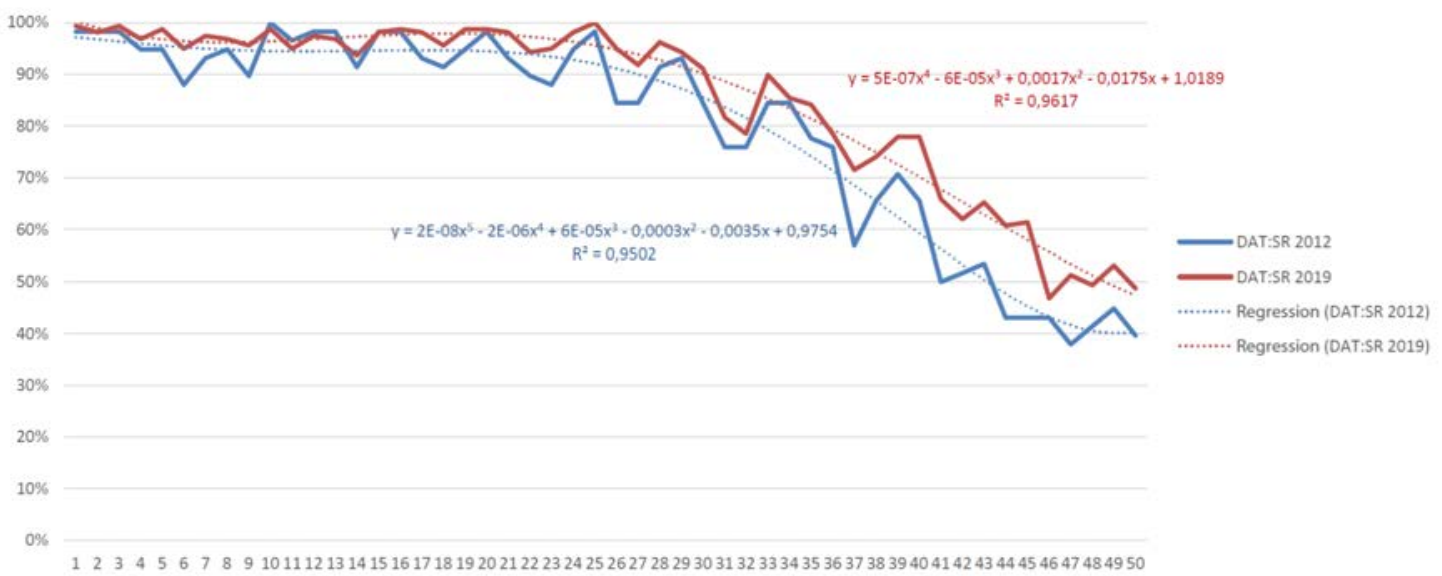

Figure 3. Percentage of students who answered each item of the Differential Aptitude Test: Space Relations

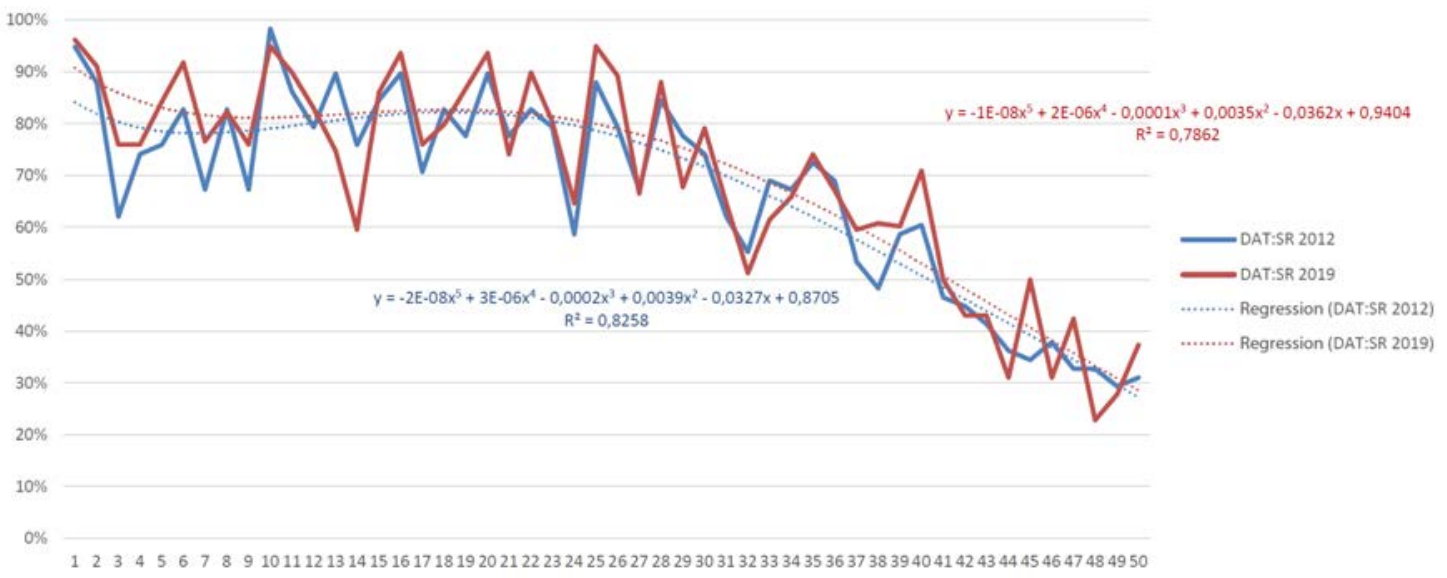

Figure 4. Percentage of students who obtained the maximum score in each item of the Differential Aptitude Test: Space Relations

\subsection{Differences between cohorts}

Differences in the median scores of the MRT and the DAT:SR of both cohorts are shown in Table 1. Students of the 2019 cohort had a significantly better performance in the MRT than the 2012 cohort $(\mathrm{U}=3406, p=.017)$. No differences emerged between cohorts in the DAT:SR.

Table 1. Differences between cohorts.

\begin{tabular}{l|c|c|c}
\hline \hline & 2012 cohort & 2019 cohort & Significance \\
\hline MRT & $18(6-40)$ & $20(4-38)$ & $\mathrm{U}=3406, \mathrm{p}=.017$ \\
\hline DAT:SR & $35(9-50)$ & $36(10-50)$ & $\mathrm{U}=4309, \mathrm{p}=.927$ \\
\hline \hline
\end{tabular}

Data are expressed in median (min-max)

\subsection{Differences between sexes}

Differences between sexes in the median scores of the MRT and the DAT:SR are shown in Table 2. Men had a significant better performance than women in the MRT $(U=3304, p=.003)$ and had comparable results in the DAT:SR. 
Table 2. Differences between sexes.

\begin{tabular}{l|l|l|l}
\hline \hline & \multicolumn{1}{|c|}{ Men } & \multicolumn{1}{c}{ Women } & \multicolumn{1}{c}{ Significance } \\
\hline MRT & $20(8-40)$ & $16.5(4-33)$ & $\mathrm{U}=3304, \mathrm{p}=.003$ \\
\hline DAT:SR & $35(9-50)$ & $36(10-46)$ & $\mathrm{U}=4026.5, \mathrm{p}=.242$ \\
\hline \hline
\end{tabular}

Data are expressed in median (min-max)

\section{DISCUSSION}

The decrease in the performance of both tests evidenced by Figure 1 to Figure 4 is supported by the evolution observed in Figure 5, which has been specifically created from the data of a previous study [22] that analysed the difficulty of the individual items of the 24-item version [23] of the MRT.

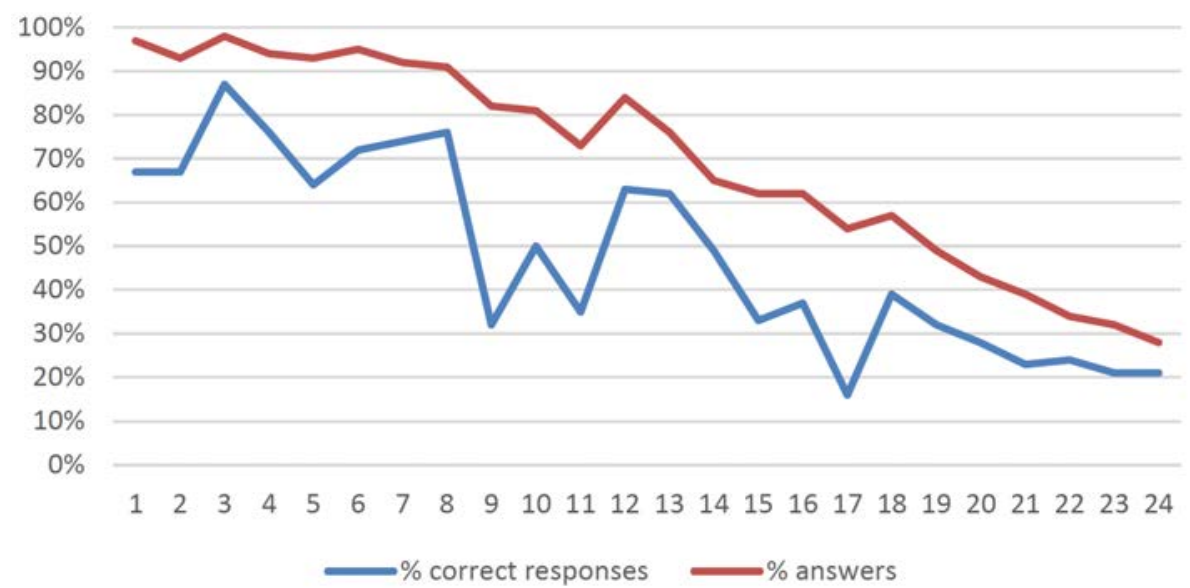

Figure 5. Performance in the Mental Rotation Test in the study by Cassie et al [22]

The higher scores in the MRT obtained by the 2019 cohort could be potentially linked to the exposure and interaction with media and interactive devices. However, it is also important to consider that the minimum score in the Spanish University Entrance Examination to enrol in the Engineering Technology undergraduate degree program at the School of Industrial Engineering of Universitat Politècnica de València increased from 9.94 points in 2012 to 11.31 points in 2019, i.e. an increment of $13.8 \%$. The higher score obtained by students of the 2019 cohort could also evidence increased spatial skills, which could explain the higher scores in the MRT. Interestingly, spatial skills have been proved to be a good predictor for success in STEM courses [24].

Regarding sex differences, our results are well aligned with previous studies [6, 21], which concluded that the largest difference between sexes is associated to the "spatial relation" subfactor. While a significant better performance has been reported for men, those results related to the "spatial visualization" component are highly variable and recurrently nonsignificant. Our results also support a previous study [25] with engineering students at a Spanish university, where MRT scores where significantly better, while there were no differences in the scores of the DAT:SR.

In conclusion, our results showed a clear worsening in the performance throughout two of the most widely used tests to assess spatial skills. Additionally, although the unbalanced number of students in both cohorts and the sex distribution, our findings support better performance in the 2019 cohort compared to the 2012 cohort, and in men compared to women.

\section{ACKNOWLEDGEMENTS}

This work has been funded by Vicerrectorado de Estudios, Calidad y Acreditación of Universitat Politècnica de València (Valencia, Spain). 


\section{REFERENCES}

[1] S. S. Metz, S. Donohue, and C. Moore, "Spatial skills: A focus on gender and engineering," Int. J. Sci. Educ., vol. 31, p. 3, 2012.

[2] J. Wai, D. Lubinski, and C. P. Benbow, "Spatial ability for STEM domains: Aligning over 50 years of cumulative psychological knowledge solidifies its importance.," J. Educ. Psychol., vol. 101, no. 4, p. 817, 2009.

[3] G. P. Adanez and A. D. Velasco, "Predicting academic success of engineering students in technical drawing from visualization test scores," J. Geom. Graph., vol. 6, no. 1, pp. 99-109, 2002.

[4] N. L. Veurink and S. A. Sorby, "Longitudinal study of the impact of requiring training for students with initially weak spatial skills," Eur. J. Eng. Educ., vol. 44, no. 1-2, pp. 153-163, 2019.

[5] S. Strong and R. Smith, "Spatial visualization: Fundamentals and trends in engineering graphics," J. Ind. Technol., vol. 18, no. 1, pp. 1-6, 2001.

[6] M. C. Linn and A. C. Petersen, "Emergence and characterization of sex differences in spatial ability: A meta-analysis," Child Dev., pp. 1479-1498, 1985.

[7] D. F. Lohman and P. C. Kyllonen, "Individual differences in solution strategy on spatial tasks," Individ. Differ. Cogn., vol. 1, pp. 105-135, 1983.

[8] L. L. Thurstone, Primary mental abilities, vol. 119. University of Chicago Press Chicago, 1938.

[9] S. Olkun, "Making connections: Improving spatial abilities with engineering drawing activities," Int. J. Math. Teach. Learn., vol. 3, no. 1, pp. 1-10, 2003.

[10] J. W. Pellegrino, D. L. Alderton, and V. J. Shute, "Understanding spatial ability," Educ. Psychol., vol. 19, no. 4, pp. 239-253, 1984.

[11] W. J. Schneider and K. S. McGrew, "The Cattell-Horn-Carroll model of intelligence," in Contemporary intellectual assessment, 3rd., D. P. Flanagan and P. L. Harrison, Eds. Guilford Press, 2012, pp. 99-144.

[12] R. Nagy-Kondor, "Spatial Ability: Measurement and Development," in Visual-spatial Ability in STEM Education: Transforming Research into Practice, M. S. Khine, Ed. Cham: Springer International Publishing, 2017, pp. 35-58.

[13] D. Voyer, S. Voyer, and M. P. Bryden, "Magnitude of sex differences in spatial abilities: A metaanalysis and consideration of critical variables.," Psychol. Bull., vol. 117, no. 2, pp. 250-270, 1995.

[14] G. Marunić and V. Glažar, "Improvement and assessment of spatial ability in engineering education," Eng. Rev. Univ. Rijeka, vol. 34, no. 2, pp. 139-150, 2014.

[15] CEEB, "Special Aptitude Test in Spatial Relations." College Entrance Examination Board New York, 1939.

[16] E. Tsutsumi, "A Mental Cutting Test using drawings of intersections," J. Geom. Graph., vol. 8, no. 1, pp. 117-126, 2004.

[17] S. G. Vandenberg and A. R. Kuse, "Mental rotations, a group test of three-dimensional spatial visualization," Percept. Mot. Skills, vol. 47, no. 2, pp. 599-604, 1978.

[18] G. K. Bennet, H. G. Seashore, and A. G. Wesman, "The differential aptitude tests: An overview," Pers. Guid. J., vol. 35, no. 2, pp. 81-91, Oct. 1956.

[19] R. B. Guay, "Purdue spatial visualization test-visualization of rotations," W. Lafayette, IN. Purdue Res. Found., 1977.

[20] S. Y. Yoon, "Psychometric properties of the revised Purdue spatial visualization tests: visualization of rotations (The Revised PSVT: R)," (Doctoral dissertation). Available from ProQuest Dissertations \& Theses Global database. (UMI No. 3480934), 2011.

[21] M. Hegarty and D. Waller, "Individual differences in spatial abilities," Cambridge Handb. visuospatial Think., pp. 121-169, 2005.

[22] A. F. Caissie, F. Vigneau, and D. A. Bors, "What does the Mental Rotation Test Measure? An Analysis of Item Difficulty and Item Characteristics," Open Psychol. J., vol. 2, no. 1, pp. 94-102, 2009. 
[23] M. Peters, B. Laeng, K. Latham, M. Jackson, R. Zaiyouna, and C. Richardson, "A redrawn vandenberg and kuse mental rotations test - different versions and factors that affect performance," Brain and Cognition, vol. 28, no. 1. pp. 39-58, 1995.

[24] S. Sorby, E. Nevin, A. Behan, E. Mageean, and S. Sheridan, "Spatial skills as predictors of success in first-year engineering," in 2014 IEEE Frontiers in Education Conference (FIE) Proceedings, 2014, pp. 1-7.

[25] N. Martín-Dorta, J. L. Saorín-Perez, and M. Contero, "Individual Differences in Spatial Abilities," in Proceedings of the XV International Conference on Human Computer Interaction - Interacción '14, C. S. González, Ed. New York, New York, USA: ACM Press, 2014, pp. 1-5. 